\title{
Biofilm Degradation of Nontuberculous Mycobacteria Formed on Stainless Steel Following Treatment with Immortelle (Helichrysum italicum) and Common Juniper (Juniperus communis) Essential Oils
}

\author{
Dolores Peruč $^{1, *}\left(\mathbb{D}\right.$, Dalibor Broznić ${ }^{2}$ (), Željka Maglica ${ }^{3}$, Zvonimir Marijanović ${ }^{4}$, Ljerka Karleuša ${ }^{5}$ and \\ Ivana Gobin ${ }^{1}$ (1)
}

1 Department of Microbiology and Parasitology, Faculty of Medicine, University of Rijeka, 51000 Rijeka, Croatia; ivana.gobin@uniri.hr

2 Department of Medical Chemistry, Biochemistry and Clinical Chemistry, Faculty of Medicine, University of Rijeka, 51000 Rijeka, Croatia; dalibor.broznic@medri.uniri.hr

3 Department of Biotechnology, University of Rijeka, 51000 Rijeka, Croatia; zeljka.maglica@uniri.hr

4 Department of Food Technology and Biotechnology, Faculty of Chemistry and Technology, University of Split, 21000 Split, Croatia; zvonimir.marijanovic@ktf-split.hr

5 Department of Physiology and Immunology, Faculty of Medicine, University of Rijeka, 51000 Rijeka, Croatia; ljerka.karleusa@medri.uniri.hr

* Correspondence: dolores.peruc@uniri.hr; Tel.: +385-(0)51-651-145; Fax: +385-(0)51-651-177

\section{check for} updates

Citation: Peruč, D.; Broznić, D.; Maglica, Ž.; Marijanović, Z.; Karleuša, L.; Gobin, I. Biofilm Degradation of Nontuberculous Mycobacteria Formed on Stainless Steel Following Treatment with Immortelle (Helichrysum italicum) and Common Juniper (Juniperus communis) Essential Oils. Processes 2021, 9, 362. https:// doi.org/10.3390/pr9020362

Academic Editors: Nicola Gargiulo and Elwira Sieniawska

Received: 30 December 2020

Accepted: 10 February 2021

Published: 16 February 2021

Publisher's Note: MDPI stays neutral with regard to jurisdictional claims in published maps and institutional affiliations.

Copyright: (c) 2021 by the authors. Licensee MDPI, Basel, Switzerland. This article is an open access article distributed under the terms and conditions of the Creative Commons Attribution (CC BY) license (https:// creativecommons.org/licenses/by/ $4.0 /)$.

\begin{abstract}
Nontuberculous mycobacteria, like other opportunistic premise plumbing pathogens, produce resistant biofilms on various surfaces in the plumbing system including pipes, tanks, and fittings. Since standard methods of water disinfection are ineffective in eradicating biofilms, research into new agents is necessary. Essential oils (EOs) have great potential as anti-biofilm agents. Therefore, the purpose of this research was to investigate the potential anti-biofilm effect of common juniper (Juniperus communis) and immortelle (Helichrysum italicum) EOs. Minimum inhibitory concentrations (MIC), minimum bactericidal concentrations (MBC), and minimum effective concentrations of EOs on $M y-$ cobacterium avium, $M$. intracellulare, and $M$. gordonae were tested. Additionally, biofilms on the surface of a stainless steel disc were treated with single or mixed concentration of EOs, in order to investigate their degeneration via the bacterial count and confocal laser scanning microscopy (CLSM). H. italicum EO showed the strongest biofilm degradation ability against all Mycobacteria strains that were tested. The strongest effect in the biofilm degradation after the single or mixed applications of EOs was observed against $M$. gordonae, followed by $M$. avium. The most resistant was the $M$. intracellulare biofilm. Synergistic combinations of J. communis and H. italicum EOs therefore seem to be an effective substance in biofilm degradation for use in small water systems such as baths or hot tubs.
\end{abstract}

Keywords: biofilm; common juniper; immortelle; nontuberculous mycobacteria; stainless steel

\section{Introduction}

Mycobacteria originated 150 million years ago [1]. The genus Mycobacterium is the only member of the family Mycobacteriaceae from the order Actinomycetales and the class Actinomycetes. Today, more than 200 species belong to the genus Mycobacterium, which include obligate and opportunistic pathogens and saprophytes [2]. Nontuberculous mycobacteria (NTM) are a heterogeneous group of environmental bacteria mainly isolated from water, soil, dust, various animals, milk, and dairy products [3]. Although mostly apathogenic, nowadays, they increasingly represent important environmental opportunistic pathogens [4]. Mycobacterium avium and M. intracellulare are members of the Mycobacterium avium complex (MAC). These are slow-growing unpigmented mycobacteria that form smooth, flat, transparent colonies. MACs are the most frequently isolated pathogenic NTM species from respiratory samples [5]. M. gordonae is a mycobacterium that forms smooth 
orange colonies and is a mostly apathogenic, saprophytic species of NTM [5,6]. In Croatia, it is one of the most common isolates from the respiratory tract, but is extremely rarely associated with clinically proven infection [7]. Inhalation of infectious aerosol is a major transmission route for pulmonary infections caused by NTM [8]. The source of infection can be drinking tap water, well water, taps in residential, hospital and laboratory areas, hot tub water, house dust, potted soil, forest soil, domestic animals, or sea water [8-10]. The presence of NTM in these sources is mainly a result of their ability to form biofilms and to survive in free-living amoebae [9]. Due to a high content of complex lipids and mycolates, the cell wall of mycobacteria is extremely hydrophobic, which greatly facilitates their binding to various surfaces and biofilm formation and contributes to their resistance to phagocytosis, disinfectants, and antimicrobial drugs [2]. The research revealed that tap water is often a source of NTM colonization and/or infection [11]. In the aquatic environment, M. avium has an exceptional ability to form biofilm [4]. As a result, this mycobacterium, along with Legionella pneumophila, Pseudomonas aeruginosa, and Acinetobacter baumannii, is classified as an opportunistic premise plumbing pathogen (OPPP) [12]. Twice as many Mycobacterium spp. were found in biofilm samples from showerheads than were found in drinking water samples. M. gordonae, M. avium, M. intracellulare, and M. xenopi were the species most frequently isolated from these biofilms, while drinking water contained significant amounts of M. gordonae, M. chelonae, M. fortuitum, and M. terrae [13,14].

Most studies comparing the formation of biofilms of slow-growing NTMs in the aquatic environment have identified three key determinants: First, NTMs can, independently, without the presence of other microorganisms, create a suitable substrate and begin biofilm formation. Second, plastic and siliconized substrates widely used in medicine and in the water supply system can be very quickly colonized with mycobacteria. Third, NTMs can produce biofilms under the conditions of low nutrient levels such as in the water supply system, without significantly impairing their growth potential [15].

The Mediterranean area is known as the natural habitat of a large number of medicinal plants that have long been utilized in traditional medicine. According to the available data, the Croatian flora consists of over 4000 species [16]. Research on the antimicrobial effect of certain plant species and natural substances, the effective concentration of which has no harmful effects on the human body, represents an important contribution to the improvement of therapeutic and preventive protocols. The biochemical and physiological properties of each plant species directly depend on its chemical composition. This primarily refers to the fact that each individual species inhabiting a particular geographical area will have a genome encoding specific enzyme system, which in turn produces a specific range of certain chemical compounds [17]. Essential oils (EO) are extracts characterized as a complex mixture of volatile constituents having a strong scent. They are formed by the secondary metabolism of plants [18]. There is substantial data in the literature on the antibacterial, antifungal, and antiviral effects of different EOs [19-21], but few studies have been made on the effects of EOs on mycobacteria [22,23].

Common juniper (Juniperus communis) is an evergreen coniferous shrub that grows in the hilly regions of the Northern Hemisphere. Its needles and dried fruit are used in traditional medicine as diuretic, uroantiseptic, carminative, digestive, and antioxidant agents [24]. The main bioactive substances in J. communis EO are: $\alpha$ - and $\beta$-pinene, $\beta$ myrcene, sabinene, limonene, terpinene-4-ol and $\beta$-caryophyllene [25-27]. Immortelle (Helichrysum italicum), a perennial flowering plant belonging to the genus Helichrysum, from the family Asteraceae, is widely distributed along the Adriatic coast and islands and is used in traditional medicine for its anti-inflammatory, antimicrobial, and antioxidant properties [28]. H. italicum EO, produced from the flowering plant, is most commonly reported to contain: $\alpha$-pinene, neryl acetate, $\beta$-curcumene, $\gamma$-curcumene, $\beta$-caryophyllene, limonene, $\alpha$-cadrene, and geranyl acetate $[17,29,30]$.

The first aim of this study was to determine the chemical compositions of J. communis and H. italicum EOs as well as to examine the antimicrobial effects of these EOs on M. avium, M. intracellulare, and M.gordonae and to determine their minimum inhibitory concentration 
(MIC) and minimum bactericidal concentration (MBC). The second aim was to examine the interaction of J. communis and H. italicum EOs on selected NTMs and their effect on the degradation of mycobacterial biofilms formed on stainless steel.

\section{Material and Methods}

\subsection{Essential Oils}

The natural EOs of common juniper (Juniperus communis) and immortelle (Helichrysum italicum) used in this research were purchased from IREX AROMA d.o.o., Zagreb, Croatia. The EOs were produced in 2018. Gas chromatography and mass spectrometry (GC/MS) analyses of EOs were done [31]. EOs have been shown to have chemical composition characteristic for the said essential oils. Each EO was dissolved in dimethylsulfoxide (DMSO; Kemika, Zagreb, Croatia) to obtain a stock suspension, which was stored in sterile glass vials in the dark at $4{ }^{\circ} \mathrm{C}$ prior to use.

\subsection{Strains and Growth Media}

American Type Culture Collection (ATCC) strains were used in these experiments: Mycobacterium avium ssp. avium (serotype 2) ATCC 25291, Mycobacterium intracellulare ATCC 13950, and Mycobacterium gordonae ATCC 14470, and were cultured as described previously $[27,32,33]$. Briefly, bacterial strains were subcultured twice in Middlebrook 7H9 broth (7H9S, Difco, Detroit, Michigan, USA) containing 10\% albumin-dextrose-catalase enrichment (ADC, Biolife Italiana, Milano, Italy) and 0.05\% Tween 80 (Biolife Italiana, Milano, Italy) at $30^{\circ} \mathrm{C}$ (M. gordonae) or $37^{\circ} \mathrm{C}$ (M. avium and M. intracellulare) for at least 14 days to obtain $10^{8} \mathrm{CFU} \mathrm{mL}{ }^{-1}$. The bacteria were kept frozen at $-80^{\circ} \mathrm{C}$ in $7 \mathrm{H} 9 \mathrm{~S}$ with $10 \%$ glycerol (Kemika, Zagreb, Croatia). For each experiment, an aliquot was thawed and subcultured in 7H9S for at least 14 days and then on Middlebrook 7H10 agar (7H10S, Difco, Detroit, Michigan, USA) with $10 \%$ oleic acid-albumin-dextrose-catalase enrichment (OADC, Biolife Italiana, Milan, Italy) and $0.05 \%$ Tween 80 at $30^{\circ} \mathrm{C}\left(\mathrm{M}\right.$. gordonae) or $37^{\circ} \mathrm{C}$ (M. avium and $M$. intracellulare) for another 14 days. The number of bacteria in the initial inocula were verified by diluting and plating the culture onto $7 \mathrm{H} 10 \mathrm{~S}$ and incubating at $30{ }^{\circ} \mathrm{C}$ (M. gordonae) or $37^{\circ} \mathrm{C}$ (M. avium and M. intracellulare) for four to six weeks, after which colonies were counted.

\subsection{Sterile Tap Water Sample}

In all experiments, tap water from the public water supply system of the city of Rijeka was used. Physicochemical parameters of tap water in Rijeka are regularly monitored by authorized Croatian testing laboratories certified to provide chemical analysis of drinking water and show values that rarely deviate. The water is colorless and odorless, with a normal temperature parameter depending on seasonal variations. It has low turbidity, neutral to slightly alkaline $\mathrm{pH}$ (from 7.5 to 8.0 ), low conductivity $\left(0.211-0.250 \mathrm{mS} \mathrm{cm}^{-1}\right.$ at $\left.20{ }^{\circ} \mathrm{C}\right)$, and moderate total hardness $\left(135 \mathrm{mg} \mathrm{L}^{-1}\right)$. According to these parameters, it is considered as medium hard. The tap water sample in a glass bottle was left at room temperature for two days to allow for dechlorination. The water sample was then autoclaved at $121^{\circ} \mathrm{C}$ for $15 \mathrm{~min}$ and cooled to room temperature and stored at $4^{\circ} \mathrm{C}$ until use.

\subsection{Checkerboard Synergy Method}

To determine the potential interaction effect of J. communis and H. italicum EOs on NTM, the checkerboard synergy method was used, as described previously [33-35]. Briefly, stock solutions and serial two-fold dilutions of each EO were prepared in 7H9S. These dilutions were arrayed in a grid pattern, with the J. communis EO dilution series running perpendicular to that of the H. italicum EO. The combinations of concentrations of each EO tested are shown in the results section (Figure 1). An inoculum of each Mycobacterium isolate $\left(10^{6} \mathrm{CFU} \mathrm{mL} \mathrm{mL}^{-1}\right)$ was prepared in $7 \mathrm{H} 9 \mathrm{~S}$ and added along with $0.015 \%$ resazurin solution (Sigma-Aldrich, Darmstadt, Germany) to wells containing diluted EOs. Positive (bacterial inoculum in 7H9S) and negative (7H9S) growth controls were prepared. Additionally, 
the antibiotic amikacin (Sigma-Aldrich, Darmstadt, Germany) was also tested against all three mycobacteria. The final concentration of DMSO as a solvent was approximately $10 \%$ and its effect was tested against the selected mycobacteria. The plates were incubated for four days under aerobic conditions at $30^{\circ} \mathrm{C}\left(\mathrm{M}\right.$. gordonae) or $37^{\circ} \mathrm{C}$ (M. avium and $\mathrm{M}$. intracellulare), and then dilutions from each well were inoculated on $7 \mathrm{H} 10 \mathrm{~S}$ in duplicate and incubated for a further four weeks. Fractional inhibitory concentration or fractional bactericidal concentration [36] and fractional inhibitory concentration index ( $\left.\mathrm{FIC}_{\mathrm{i}}\right)$ or fractional bactericidal concentration index (FBCi) were determined as previously described by Bassole et al. and White et al. [20,37]. Baes on the $\mathrm{FIC}_{\mathrm{i}}$ or $\mathrm{FBC}_{\mathrm{i}}$ values, a combination of EOs was considered synergistic if $\mathrm{FIC}_{\mathrm{i}} / \mathrm{FBC}_{\mathrm{i}}$ was $\leq 0.5$, additive if $\mathrm{FIC}_{\mathrm{i}} / \mathrm{FBC}_{\mathrm{i}}$ was $>0.5$ and $\leq 1.0$, indifferent when $\mathrm{FIC}_{\mathrm{i}} / \mathrm{FBC}_{\mathrm{i}}$ was $>1.0$ and $\leq 4$, and antagonistic if $\mathrm{FBC}_{\mathrm{i}}$ was $>4$ [38].

\subsection{Effect of Juniperus communis and Helichrysum italicum Essential Oils on Mycobacterial Biofilm on Stainless Steel Discs in Sterilized Tap Water}

The effect of different concentrations of J. communis and H. italicum EOs as well as synergistic or additive combinations of these EOs on the degradation of the biofilm of $M$. avium, M. intracellulare, and M. gordonae was tested on stainless steel discs (diameter, $5 \mathrm{~mm}$; American Iron and Steel Institute (AISA) type 316) in sterilized tap water (STW). The discs were left overnight in 70\% ethanol (Kemika, Zagreb, Croatia), rinsed with distilled water, air dried, dry heat sterilized at $160{ }^{\circ} \mathrm{C}$, and then aseptically transferred to the wells of microtiter plates (24-well microtiter plates, Falcon, Becton Dickinson, Franklin Lakes, New Jersey, USA). Then, a suspension of $10^{6} \mathrm{CFU} \mathrm{mL} \mathrm{mL}^{-1}$ of mycobacterial cells was prepared in STW and added to wells containing discs to form a biofilm. The plates were incubated for $72 \mathrm{~h}$ at $30^{\circ} \mathrm{C}$ (M. gordonae) or $37^{\circ} \mathrm{C}$ (M. avium and M. intracellulare), then carefully washed with STW to remove planktonic cells and transferred to new microtiter plates. J. communis EO or H. italicum EO in MIC, $2 \times \mathrm{MIC}$ and their synergistic (for M. avium and M. gordonae) or additive (for $M$. intracellulare) combinations were added to the biofilm and were then incubated for an additional $24 \mathrm{~h}$ at $30^{\circ} \mathrm{C}$ (M. gordonae) or $37^{\circ} \mathrm{C}$ (M. avium and $M$. intracellulare). Untreated mycobacterial cells served as controls. Discs were then washed three times with STW and sonicated in a water bath (Bactosonic, Bandelin, Berlin, Germany) at $40 \mathrm{kHz}$ for $1 \mathrm{~min}$. Mycobacteria were quantified by culturing on $7 \mathrm{H} 10 \mathrm{~S}$ at $37{ }^{\circ} \mathrm{C}$ for 14 days, until colonies were observed. The percentage of degradation in the biofilm on the stainless steel discs that resulted from this was determined as described previously by Teanpaisan et al. [39]:

$$
\text { Percentage of degradation }(\%)=1-\frac{\text { CFU of sample treated with } \mathrm{EO}}{\text { CFU of negative control }} \times 100
$$

\subsection{Determination of Cell Viability in Biofilms Growing on Stainless Steel Coupons, after Treatment with Juniperus communis and Helichrysum italicum Essential Oils}

Cell viability assays were performed (Live/Dead BacLight Bacterial Viability Kit; Invitrogen, Carlsbad, California, USA) according to the manufacturer's protocol. Briefly, a biofilm of $M$. avium and $M$. intracellulare was grown for three days on round stainless steel discs. These were exposed to the individual effect of J. communis or H. italicum EOs, in synergistic or additive combinations, for $22 \mathrm{~h}$ at $37^{\circ} \mathrm{C}$. The stainless steel discs were carefully washed with STW to remove planktonic cells. Fluorescent-stain working solution was prepared by adding $3 \mu \mathrm{L}$ of the SYTO $^{\circledR} 9$ stain and $3 \mu \mathrm{L}$ of the propidium iodide (PI) stain to $1 \mathrm{~mL}$ of filter-sterilized water. This staining solution was then applied to the surface of the disc and incubated in the dark for $15 \mathrm{~min}$. The samples were then washed with sterile saline to remove excess dye. Fluorescence from the stained cells was observed using an Olympus confocal microscope FV300 (Olympus Optical Company, Tokyo, Japan) with a 40x LCPlanF objective. The excitation/emission maxima for these dyes are around $480 / 500 \mathrm{~nm}$ for the SYTO ${ }^{\circledR} 9$ stain and 490/635 nm for PI. Simultaneous dual-channel imaging was used to display green and red fluorescence. The obtained images were saved 
in TIFF format, and further processed using ImageJ 1.47. A minimum of three images per term were analyzed.

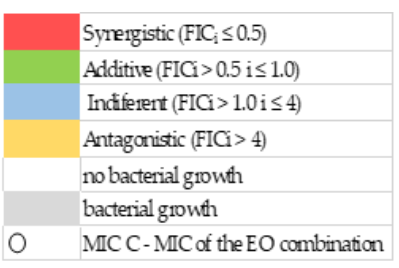

H. italicum $\mathrm{EO} \mathrm{mg} \mathrm{mL}^{-1}$

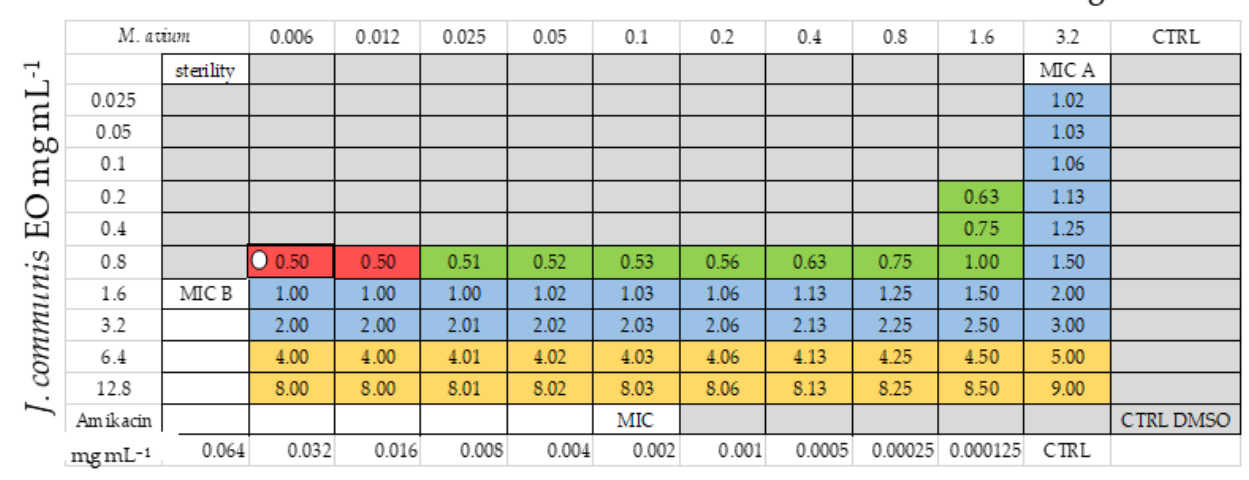

H. italicum $\mathrm{EO} \mathrm{mg} \mathrm{mL}^{-1}$

\begin{tabular}{|c|c|c|c|c|c|c|c|c|c|c|c|c|c|}
\hline \multirow[b]{2}{*}{7} & \multicolumn{2}{|c|}{ M. vitracellulare } & \multirow[t]{2}{*}{0.006} & \multirow[t]{2}{*}{0.012} & \multirow[t]{2}{*}{0.025} & \multirow[t]{2}{*}{0.05} & \multirow[t]{2}{*}{0.1} & \multirow[t]{2}{*}{0.2} & \multirow[t]{2}{*}{0.4} & \multirow[t]{2}{*}{0.8} & \multirow[t]{2}{*}{1.6} & \multirow{2}{*}{$\begin{array}{c}3.2 \\
\text { MIC A }\end{array}$} & \multirow[t]{2}{*}{ CTRL } \\
\hline & & sterility & & & & & & & & & & & \\
\hline 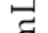 & 0.025 & & & & & & & & & & & 1.02 & \\
\hline A & 0.05 & & & & & & & & & & & 1.03 & \\
\hline$\widetilde{q}$ & 0.1 & & & & & & & & & & & 1.06 & \\
\hline & 0.2 & & & & & & & & & & & 1.13 & \\
\hline II & 0.4 & & & & & & & & & & & 1.25 & \\
\hline $\mathscr{2}$ & 0.8 & & & & & & & & & & 01.00 & 1.50 & \\
\hline$\Xi$ & 1.6 & MIC B & 1.00 & 1.00 & 1.01 & 1.02 & 1.03 & 1.06 & 1.13 & 1.25 & 1.50 & 2.00 & \\
\hline I & 3.2 & & 2.00 & 2.00 & 2.01 & 2.02 & 2.03 & 2.06 & 2.13 & 2.25 & 2.50 & 3.00 & \\
\hline 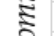 & 6.4 & & 4.00 & 4.00 & 4.01 & 4.02 & 4.03 & 4.06 & 4.13 & 4.25 & 4.50 & 5.00 & \\
\hline 8 & 12.8 & & 8.00 & 8.00 & 8.01 & 8.02 & 8.03 & 8.06 & 8.13 & 8.25 & 8.50 & 9.00 & \\
\hline$\dot{r}$ & Amikacin & & & & & & & MIC & & & & & CTRLDMSO \\
\hline & $\mathrm{mgmL}^{-1}$ & 0.064 & 0.032 & 0.016 & 0.008 & 0.004 & 0.002 & 0.001 & 0.0005 & 0.00025 & 0.00012 & CTRL & \\
\hline
\end{tabular}

H. italicum $\mathrm{EO} \mathrm{mg} \mathrm{mL}^{-1}$

\begin{tabular}{|c|c|c|c|c|c|c|c|c|c|c|c|c|c|}
\hline & \multicolumn{2}{|c|}{ M. gordonae } & \multirow[t]{2}{*}{0.025} & \multirow[t]{2}{*}{0.05} & \multirow[t]{2}{*}{0.1} & \multirow[t]{2}{*}{0.2} & \multirow[t]{2}{*}{0.4} & \multirow[t]{2}{*}{0.8} & \multirow[t]{2}{*}{1.6} & \multirow{2}{*}{$\frac{3.2}{\mathrm{MICA}}$} & \multirow[t]{2}{*}{6.4} & \multirow[t]{2}{*}{12.8} & \multirow[t]{2}{*}{ CTRL } \\
\hline \multirow{5}{*}{ 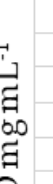 } & & sterility & & & & & & & & & & & \\
\hline & 0.025 & & & & & & & & & 1.02 & 2.02 & 4.02 & \\
\hline & 0.05 & & & & & & & & & 1.03 & 2.03 & 4.03 & \\
\hline & 0.1 & & & & & & & $\mathrm{O} 0.31$ & 0.56 & 1.06 & 2.06 & 4.06 & \\
\hline & 0.2 & & & & & & 0.25 & 0.38 & 0.63 & 1.13 & 2.13 & 4.13 & \\
\hline \multirow{7}{*}{2} & 0.4 & & 0.26 & 0.27 & 0.28 & 0.31 & 0.38 & 0.50 & 0.75 & 1.25 & 2.25 & 4.25 & \\
\hline & 0.8 & & 0.51 & 0.52 & 0.53 & 0.56 & 0.63 & 0.75 & 1.00 & 1.50 & 2.50 & 4.50 & \\
\hline & 1.6 & MIC B & 1.01 & 1.02 & 1.03 & 1.06 & 1.13 & 1.25 & 1.50 & 2.00 & 3.00 & 5.00 & \\
\hline & 3.2 & & 2.01 & 2.02 & 2.03 & 2.06 & 2.13 & 2.25 & 2.50 & 3.00 & 4.00 & 6.00 & \\
\hline & 6.4 & & 4.01 & 4.02 & 4.03 & 4.06 & 4.13 & 4.25 & 4.50 & 5.00 & 6.00 & 8.00 & \\
\hline & 12.8 & & 8.01 & 8.02 & 8.03 & 8.06 & 8.13 & 8.25 & 8.50 & 9.00 & 10.00 & 12.00 & \\
\hline & Am ikacin & & & & & & & & MIC & & & & CTRLDMSO \\
\hline & $\mathrm{mg} \mathrm{mL}^{-1}$ & 0.064 & 0.032 & 0.016 & 0.008 & 0.004 & 0.002 & 0.001 & 0.0005 & 0.00025 & 0.000125 & CTRL & \\
\hline
\end{tabular}

Figure 1. Checkerboard synergy method for the potential interaction of J. communis and $H$. italicum EOs on nontuberculous mycobacteria (NTM). MIC—-minimal inhibitory concentration; FICfractional inhibitory concentration; $\mathrm{FIC}_{\mathrm{i}}$-fractional inhibitory concentration index; $\mathrm{CTRL}-$ control; EO—essential oil. 


\subsection{Statistical Analysis}

All assays were repeated three times. Experimental data were expressed as means with standard deviations and analyzed using STATISTICA commercial software, 12.0 (StatSoft, Tulsa, OK, USA). Differences between groups of samples were analyzed using the Kruskal-Wallis ANOVA on ranks test, while the effects of EOs on mycobacterium were tested using the Mann-Whitney U test. Differences with $p<0.05$ were considered to be statistically significant.

\section{Results}

\subsection{Checkerboard Synergy Method}

The MIC and MBC values obtained for J. communis and H. italicum EOs against $M$. avium, $M$. intracellulare, and $M$. gordonae were $1.6 \mathrm{mg} \mathrm{mL}^{-1}$ and $3.2 \mathrm{mg} \mathrm{mL}^{-1}$, respectively (Figures 1 and 2). For the control antibiotic, amikacin, MIC was $0.002 \mathrm{mg} \mathrm{mL}^{-1}$ for $M$. avium, $0.001 \mathrm{mg} \mathrm{mL}^{-1}$ for $M$. intracellulare, and $0.0005 \mathrm{mg} \mathrm{mL}^{-1}$ for $M$. gordonae (Figure 1). The DMSO growth control showed that the concentration applied did not affect the growth of the mycobacteria being tested.

The best effective combination of low synergistic combinations of the EOs to achieve a high efficacy against $M$. avium in the checkerboard synergy method was $0.8 \mathrm{mg} \mathrm{mL}^{-1}$ (1/2 of the MIC) for J. communis EO, 0.006 (1/512 of the MIC) and $0.012 \mathrm{mg} \mathrm{mL}^{-1}(1 / 256$ of the MIC) for H. italicum EO. A combination of $0.8 \mathrm{mg} \mathrm{mL}^{-1} \mathrm{~J}$. communis EO with $0.006 \mathrm{mg}$ $H$. italicum EO represents the MIC for this pair of EOs against $M$. avium. A combination of these EOs only showed an additive effect against $M$. intracellulare, with the lowest concentrations of these combined EOs (MIC of the EO combination) being $0.8 \mathrm{mg} \mathrm{mL}^{-1}$ $\left(1 / 2\right.$ of the MIC) for J. communis and $1.6 \mathrm{mg} \mathrm{mL}^{-1}(1 / 2 \times \mathrm{MIC})$ for H. italicum. MIC of the combined EOs against $M$. gordonae was J. communis EO in concentrations of $0.1 \mathrm{mg} \mathrm{mL}^{-1}$ (1/16 of the MIC) or $0.2 \mathrm{mg} \mathrm{mL}^{-1}(1 / 8$ of the MIC) and H. italicum in concentrations of $0.4 \mathrm{mg} \mathrm{mL}^{-1}$ (1/8 of the MIC) or $0.8 \mathrm{mg} \mathrm{mL}^{-1}$ (1/4 of the MIC). Nine possible synergistic combinations were found against $M$. gordonae. The combinations of EOs that showed a synergistic inhibitory effect against $M$. avium, also had a synergistic bactericidal effect (MBC of the EO combination, Figure 2). Against M. intracellulare, no synergistic or additive bactericidal effect of EO combinations was observed. The combinations of $0.4 \mathrm{mg} \mathrm{mL}^{-1}$ J. communis $\mathrm{EO}$ and $0.025 \mathrm{mg} \mathrm{mL}^{-1}$ or $0.8 \mathrm{mg} \mathrm{mL}^{-1}$ H. italicum EO showed synergistic bactericidal effect against $M$. gordonae. The $\mathrm{MBC}$ for amikacin was $0.004 \mathrm{mg} \mathrm{mL}^{-1}$ against M. avium and $M$. intracellulare and $0.008 \mathrm{mg} \mathrm{mL}^{-1}$ against $M$. gordonae.

\subsection{Effect of Juniperus communis and Helichrysum italicum Essential Oils on Mycobacterial} Biofilm on Stainless Steel Discs in Sterilized Tap Water

As can be seen in Figure 3, H. italicum EO was more effective than J. communis EO at degrading biofilm formed in STW on stainless steel AISI 316 discs for all treatments of mycobacteria. Almost all of the treatments (excluding the concentration of J. communis MIC for M. avium and M. intracellulare) caused statistically significant biofilm degradation $(p<0.05)$ using both EOs, when compared to the control group. In the control group, the $2 \times$ MIC concentration of $H$. italicum EO led to the most substantial degradation of the biofilm. No statistically significant differences were found in M. avium and M. intracellulare biofilm degradation with $\mathrm{H}$. italicum $\mathrm{EO}$ at concentrations of either the MIC and $2 \times$ MIC (Figure 3a,b). In contrast, the M. gordonae (Figure 3c) biofilm showed statistically significant biofilm degradation using either the MIC or $2 \times$ MIC of H. italicum EO $(p<0.05)$. J. communis EO demonstrated a lower effectiveness on biofilm degradation in all treatments and no statistically significant differences were found for any of the mycobacteria.

Subinhibitory synergistic concentrations of J. communis and H. italicum EO did not degrade biofilms of M. gordonae formed on stainless steel discs in STW in a statistically significant manner (Figure 4c). Furthermore, significant degradation of M. avium biofilm by J. communis and H. italicum EOs was observed using concentrations of $0.8 \mathrm{mg} \mathrm{mL}^{-1}$ and/or $0.012 \mathrm{mg} \mathrm{mL}^{-1}$ (Figure 4a). Meanwhile, a subinhibitory concentration of H. italicum 
EO (1.6 mg mL $\left.\mathrm{m}^{-1}\right)$ degraded biofilms formed by M. intracellulare $(p<0.05$; Figure $4 \mathrm{~b})$. The combination of subinhibitory concentrations of J. communis and H. italicum EOs had a significant effect $(p<0.05)$ on the degradation of all mycobacteria biofilms formed on stainless steel discs.

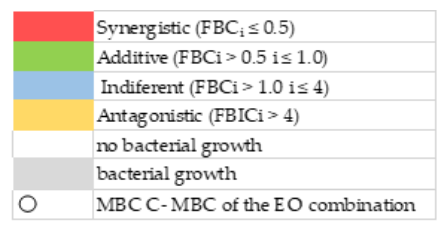

\section{H. italicum $\mathrm{EO} \mathrm{mg} \mathrm{mL}^{-1}$}

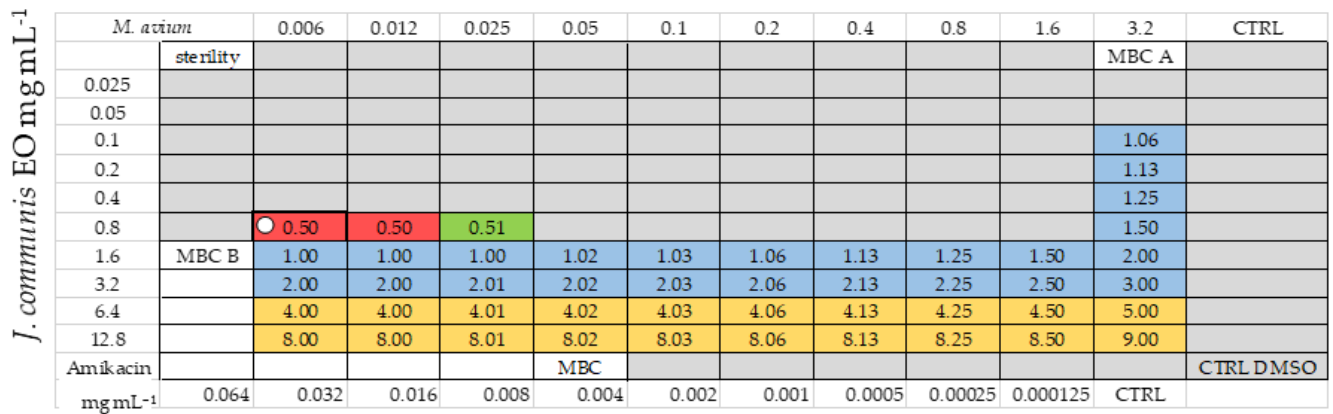

H. italicum $\mathrm{EO} \mathrm{mg} \mathrm{mL}^{-1}$

\begin{tabular}{|c|c|c|c|c|c|c|c|c|c|c|c|c|}
\hline \multicolumn{2}{|c|}{ M. intracellulare } & \multirow[t]{2}{*}{0.006} & \multirow[t]{2}{*}{0.012} & \multirow[t]{2}{*}{0.025} & \multirow[t]{2}{*}{0.05} & \multirow[t]{2}{*}{0.1} & \multirow[t]{2}{*}{0.2} & \multirow[t]{2}{*}{0.4} & \multirow[t]{2}{*}{0.8} & \multirow[t]{2}{*}{1.6} & \multirow{2}{*}{$\frac{3.2}{\mathrm{MBC} A}$} & \multirow[t]{2}{*}{ CTRL } \\
\hline & sterility & & & & & & & & & & & \\
\hline 0.025 & & & & & & & & & & & & \\
\hline 0.05 & & & & & & & & & & & & \\
\hline 0.1 & & & & & & & & & & & & \\
\hline 0.2 & & & & & & & & & & & & \\
\hline 0.4 & & & & & & & & & & & & \\
\hline 0.8 & & & & & & & & & & & & \\
\hline 1.6 & MBC B & O 1.00 & 1.00 & 1.01 & & & & & & & 2.00 & \\
\hline 3.2 & & 2.00 & 2.00 & 2.01 & 2.02 & 2.03 & 2.06 & 2.13 & 2.25 & 2.50 & 3.00 & \\
\hline 6.4 & & 4.00 & 4.00 & 4.01 & 4.02 & 4.03 & 4.06 & 4.13 & 4.25 & 4.50 & 5.00 & \\
\hline 12.8 & & 8.00 & 8.00 & 8.01 & 8.02 & 8.03 & 8.06 & 8.13 & 8.25 & 8.50 & 9.00 & \\
\hline Amikacin & & & & & MBC & & & & & & & IRL DMS \\
\hline $\mathrm{mg} \mathrm{mL}^{-1}$ & 0.064 & 0.032 & 0.016 & 0.008 & 0.004 & 0.002 & 0.001 & 0.0005 & 0.00025 & 0.00012 & CTRL & \\
\hline
\end{tabular}

H. italicum $\mathrm{EO} \mathrm{mg} \mathrm{mL}^{-1}$

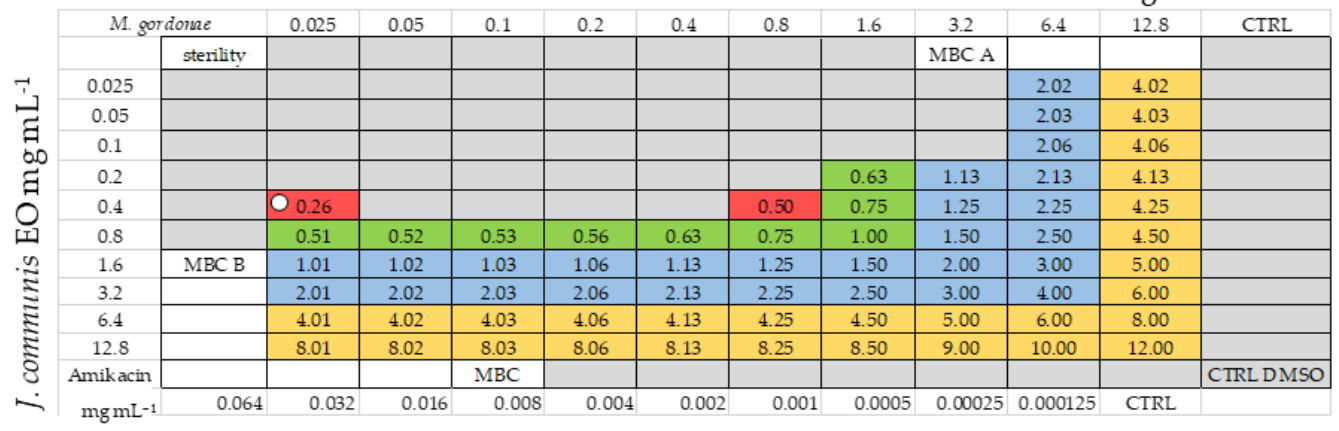

Figure 2. Checkerboard synergy method for the potential interaction of J. communis and H. italicum EOs on NTM. MBC - minimal inhibitory concentration; FBC - fractional inhibitory concentration; $\mathrm{FBC}_{\mathrm{i}}$-fractional inhibitory concentration index; CTRL—control; EO—essential oil. 

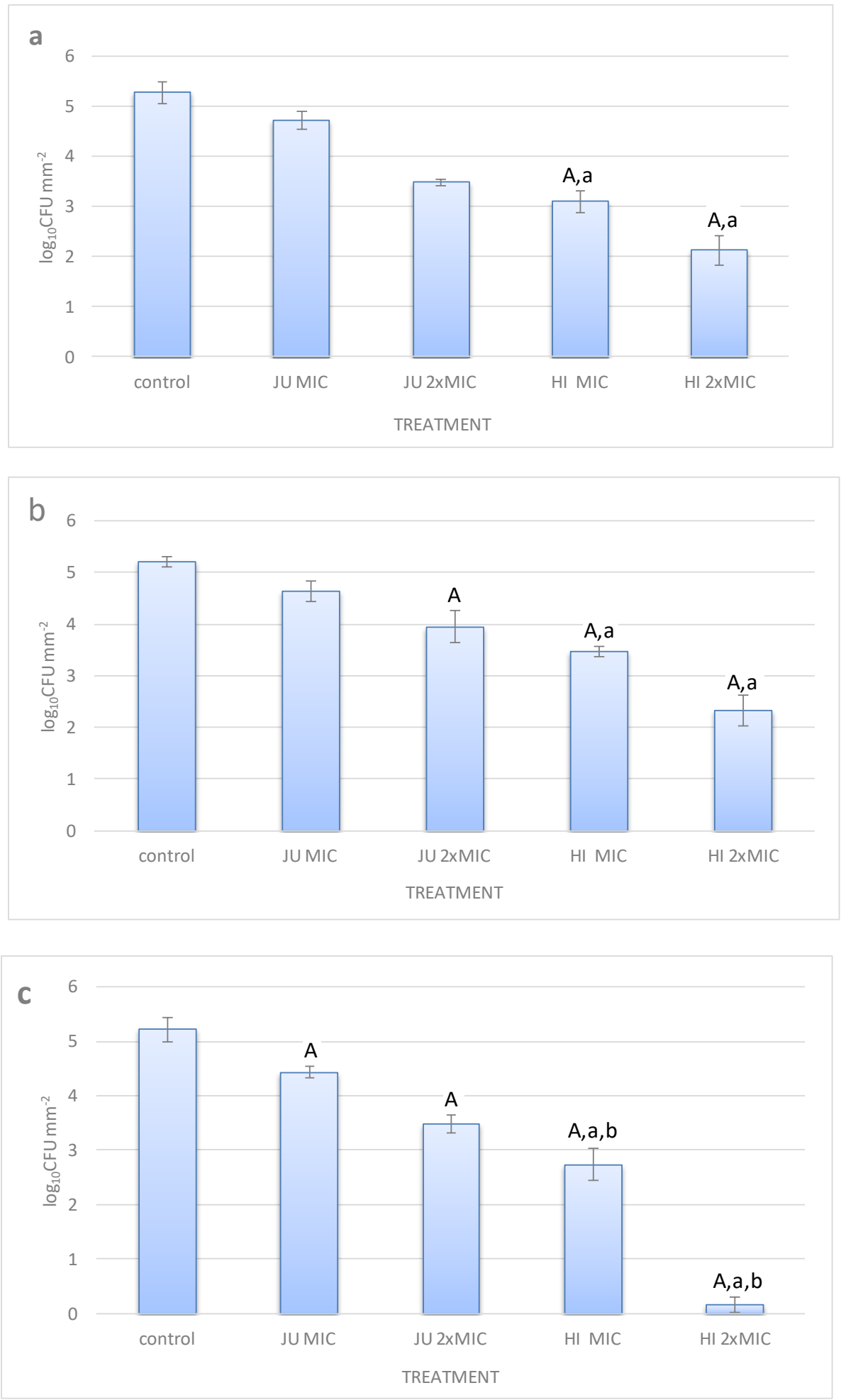

Figure 3. Effect of the MIC and $2 \times$ MIC in $\mathrm{mg} \mathrm{mL}^{-1}$ of J. communis and H. italicum EOs on the degradation of biofilms of M. avium (a), M. intracellulare (b), and M. gordonae (c) formed on stainless steel (AISI316) discs. Untreated mycobacterial cells served as controls. MIC-minimum inhibitory concentration; CFU—colony forming unit; JU—Juniperus communis; HI-Helichrysum italicum. The experiment was repeated three times in duplicate and the mean $\pm \mathrm{SD}$ is shown. Mean values marked with an uppercase letter A were significantly different compared to the control group. Mean values marked with lowercase letter a represent significant differences within different groups of EOs $(p<0.05)$. 


\subsection{Percentage of Degradation of Mycobacterial Biofilms on Stainless Steel Discs}

Table 1 shows the degradation (shown as percentages) of NTM biofilms grown on stainless steel discs caused by different concentrations of J. communis and H. italicum EOs, both individually and in combination. H. italicum $\mathrm{EO}$ at concentrations of $2 \times \mathrm{MIC}$ and MIC was more effective at degrading biofilms of all three NTMs compared to J. communis EO. A concentration of $1 / 256 \times$ MIC $\left(0.012 \mathrm{mg} \mathrm{mL}^{-1}\right)$ of $H$. italicum EO caused a higher percentage of M. avium biofilm degradation (87.4\%) than the MIC and $1 / 2 \times$ MIC of $J$. communis EO (72.1\% and $86.8 \%)$. However, subinhibitory concentrations of these EOs in combination caused a very high percentage of biofilm degradation of selected NTMs $(>98.2 \%)$. J. communis $\mathrm{EO}$ at a concentration of $1 / 2 \times \mathrm{MIC}$, plus $\mathrm{H}$. italicum $\mathrm{EO}$ at a concentration of only $1 / 256 \times$ MIC $\left(0.012 \mathrm{mg} \mathrm{mL}^{-1}\right)$ or $1 / 512 \times$ MIC $\left(0.006 \mathrm{mg} \mathrm{mL}^{-1}\right)$ caused a degree of degradation of $M$. avium biofilm comparable to that of $2 \times$ MIC of $J$. communis EO. Subinhibitory concentrations, $1 / 8 \times$ MIC and 1/2 MIC, of these EOs caused the degradation of $98.9 \%$ and $99.9 \%$ of three-day-old biofilms of $M$. intracellulare and $M$. gordonae, respectively.

3.4. Cell Viability of Biofilm on Stainless Steel Discs Treated with Juniperus communis and Helichrysum italicum Essential Oils

In order to further investigate the anti-biofilm properties of J. communis and H. italicum EOs, confocal laser scanning microscopy (CLSM) analyses were performed (Figure 5). Some regions of the biofilm appeared yellow because of overlapping green and red cells.

The CLSM results indicate a strong synergistic effect of J. communis and H. italicum EOs on biofilm eradication of both bacterial strains. M. intracellulare was more sensitive, with more total red fluorescence (154.7 AU) than M. avium (137.9 AU). Individual treatment with $H$. italicum $\mathrm{EO}$ showed a better anti-biofilm effect than that with J. communis $\mathrm{EO}$ on both Mycobacterium species, although M. intracellulare was again the more sensitive species.

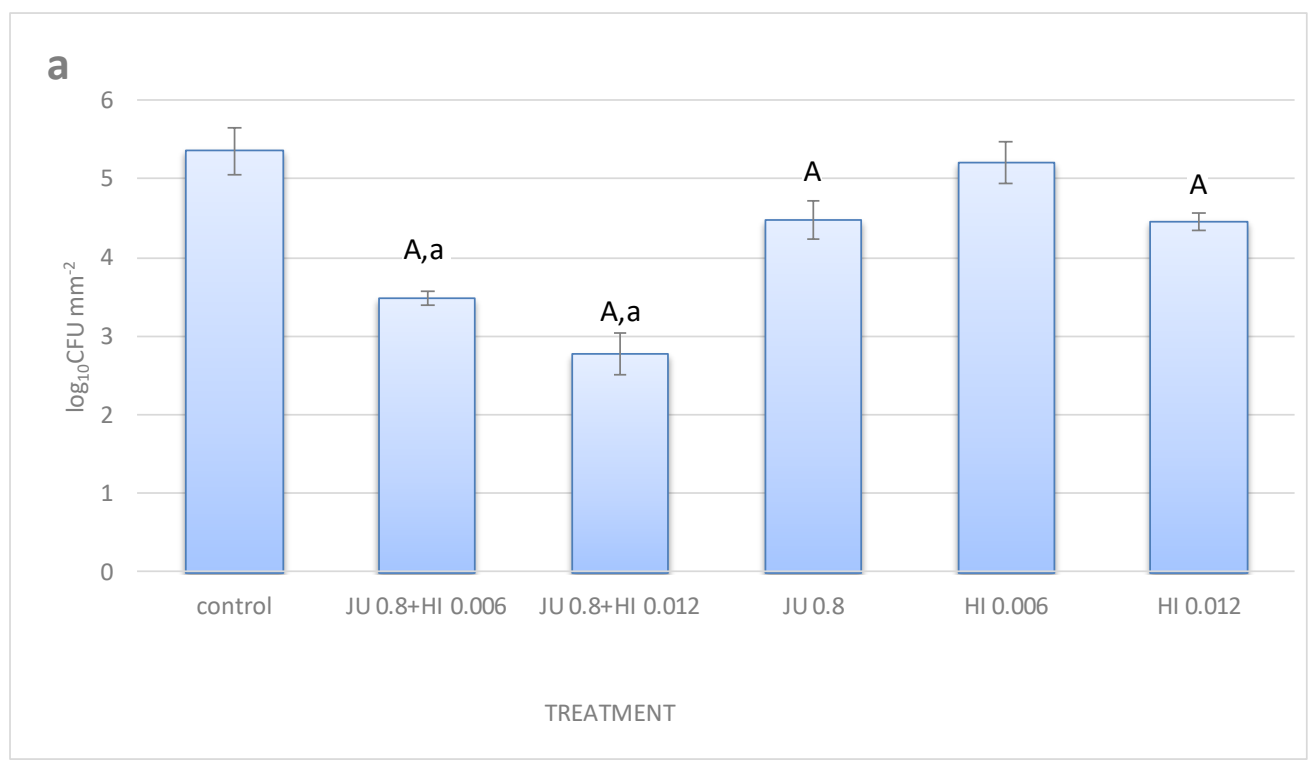

Figure 4. Cont. 

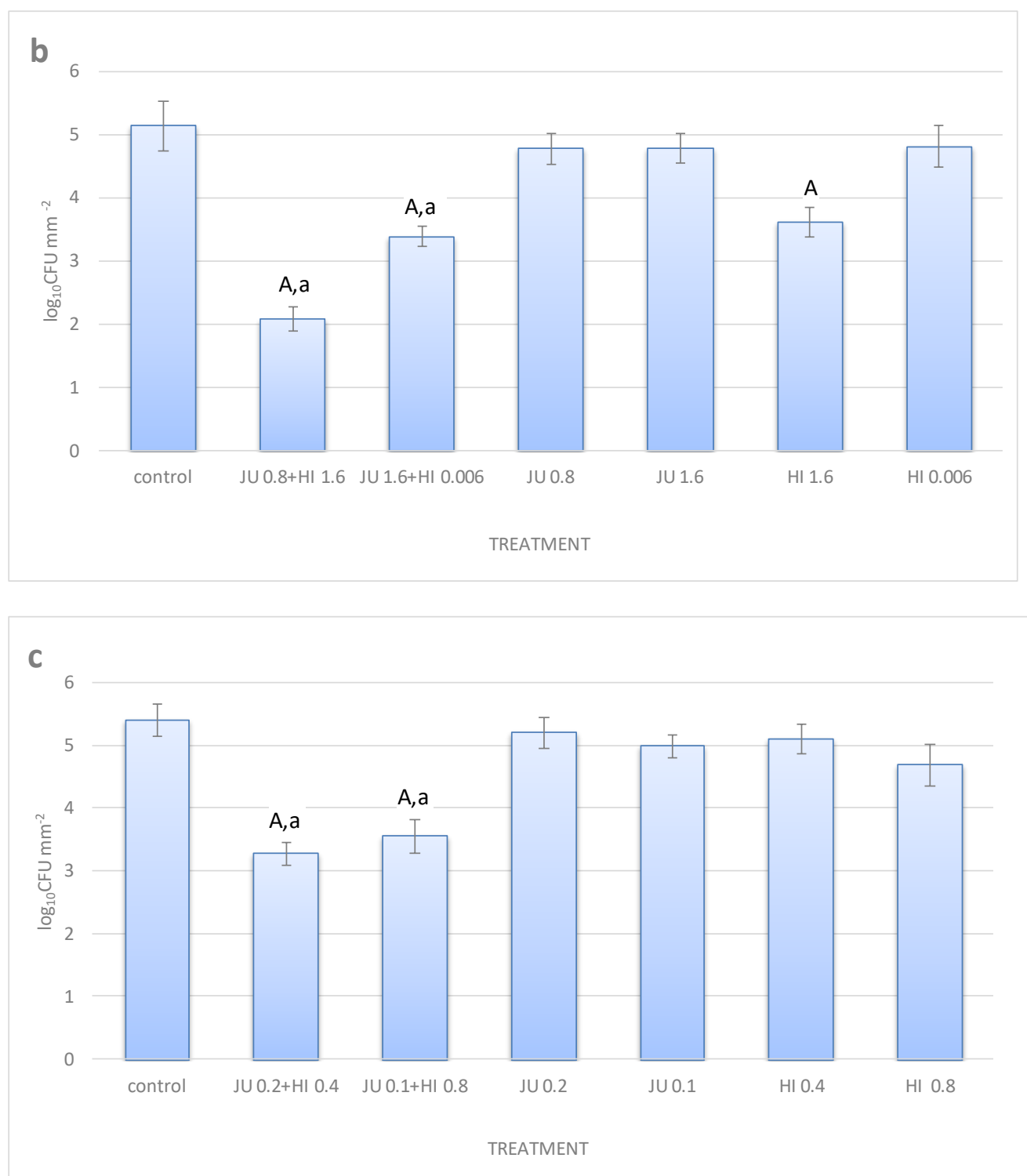

Figure 4. Effect of synergistic or additive concentrations of J. communis and H. italicum EOs in $\mathrm{mg}$ $\mathrm{mL}^{-1}$ on biofilm degradation of M. avium (a), M. intracellulare (b), and M. gordonae (c) formed on stainless steel discs. Untreated mycobacterial cells served as controls. MIC-minimum inhibitory concentration; $\mathrm{CFU}$-colony forming unit; JU—Juniperus communis; HI-Helichrysum italicum. The experiment was repeated three times in duplicate and the mean \pm SD is shown. Mean values marked with an uppercase letter A were significantly different compared to the control group. Mean values marked with a lowercase letter a represent significant differences in synergistic and individual groups of EOs $(p<0.05)$.

Table 1. Percentage of degradation (\%) of mycobacterial biofilms on stainless steel discs after treatment with J. communis $\mathrm{EO}$ and/or H. italicum EOs.

\begin{tabular}{cccc}
\hline Treatment & M. avium & M. intracellulare & M. gordonae \\
\hline H. italicum EO $\left(\mathrm{mg} \mathrm{mL}^{-\mathbf{1}}\right)$ & & & \\
\hline $\mathbf{6 . 4}$ & 99.9 & 99.9 & 99.9 \\
\hline $\mathbf{3 . 2}$ & 99.3 & 98.2 & 99.6 \\
\hline $\mathbf{1 . 6}$ & $\mathrm{ND}$ & 96.9 & $\mathrm{ND}$ \\
\hline
\end{tabular}


Table 1. Cont.

\begin{tabular}{cccc}
\hline Treatment & M. avium & M. intracellulare & M. gordonae \\
\hline $\mathbf{0 . 8}$ & ND & ND & 81.0 \\
\hline $\mathbf{0 . 4}$ & ND & ND & 49.7 \\
\hline $\mathbf{0 . 0 1 2}$ & 87.4 & ND & ND \\
\hline $\mathbf{0 . 0 0 6}$ & 71.1 & 52.8 & ND \\
\hline J. communis EO $\left(\mathbf{m g ~ m L}^{-1}\right)$ & & & \\
\hline $\mathbf{3 . 2}$ & 98.5 & 94.5 & 98.2 \\
\hline $\mathbf{1 . 6}$ & 72.1 & 72.5 & 83.6 \\
\hline $\mathbf{0 . 8}$ & 86.8 & 57.0 & $\mathrm{ND}$ \\
\hline $\mathbf{0 . 2}$ & $\mathrm{ND}$ & $\mathrm{ND}$ & 37.2 \\
\hline $\mathbf{0 . 1}$ & $\mathrm{ND}$ & $\mathrm{ND}$ & 61.2 \\
\hline
\end{tabular}

\begin{tabular}{|c|c|c|c|}
\hline \multicolumn{4}{|c|}{$\begin{array}{l}\text { H. italicum EO/J. communis EO } \\
\qquad\left(\mathrm{mg} \mathrm{mL}^{-1}\right)\end{array}$} \\
\hline $0.006 / 0.8$ & 98.7 & ND & ND \\
\hline $0.012 / 0.8$ & 99.4 & ND & ND \\
\hline $1.6 / 0.8$ & ND & 99.9 & ND \\
\hline $0.006 / 1.6$ & ND & 98.2 & ND \\
\hline $0.4 / 0.2$ & ND & ND & 98.9 \\
\hline $0.8 / 0.1$ & ND & ND & 98.6 \\
\hline
\end{tabular}

ND—not determined; EO—essential oil.
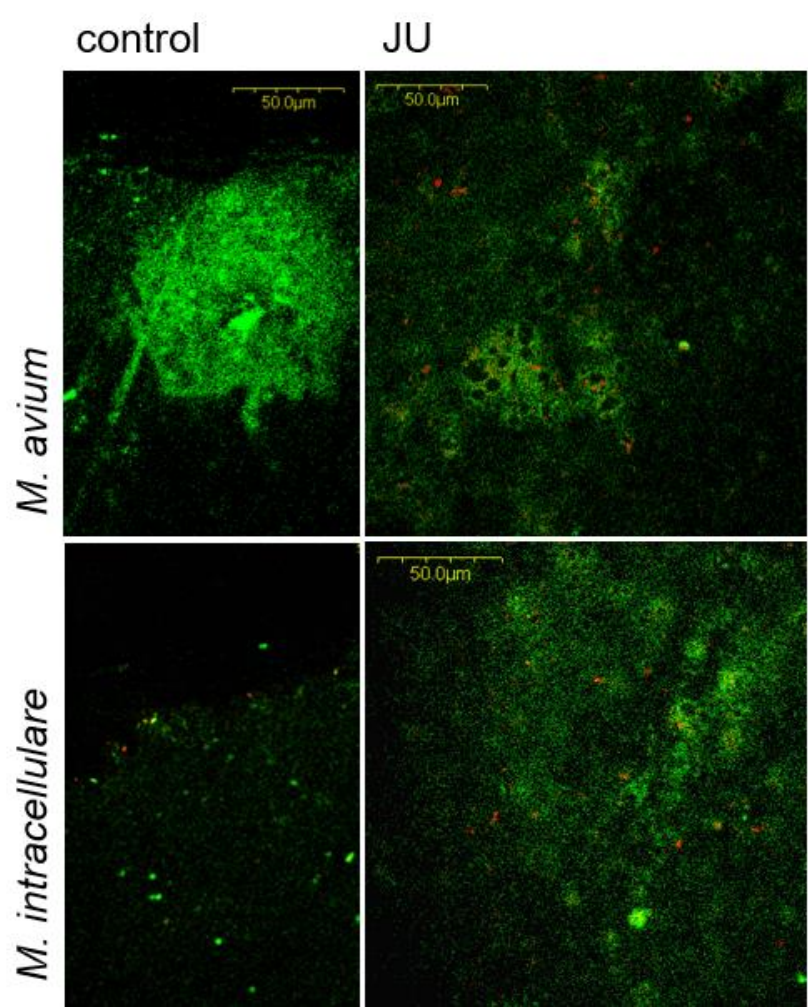

$\mathrm{H}$

$\mathrm{JU}+\mathrm{HI}$
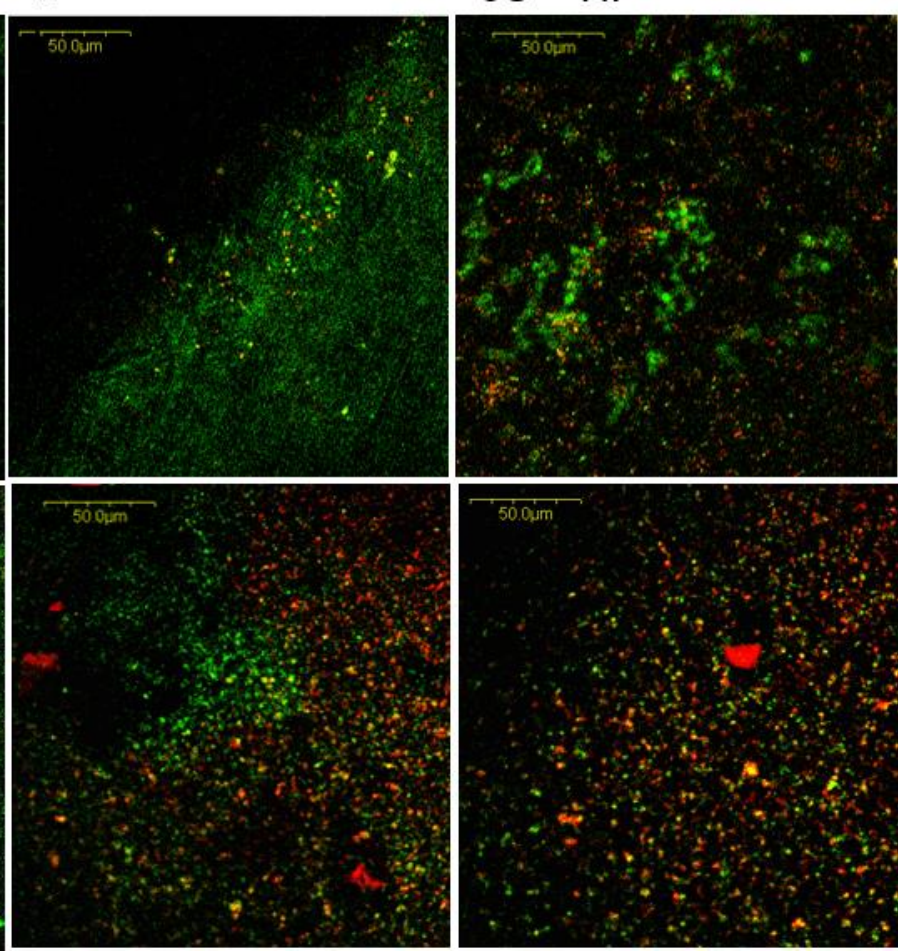

Figure 5. Live/dead stained images of Mycobacterium biofilms grown on stainless steel discs, performed by confocal laser scanning microscopy (CLSM) after treatment with J. communis (JU) and/or H. italicum (HI) EOs. M. avium was treated with JU $0.8 \mathrm{mg} \mathrm{mL}^{-1}$ and/or HI $0.012 \mathrm{mg} \mathrm{mL}^{-1}$; M. intracellulare was treated with JU $0.8 \mathrm{mg} \mathrm{mL}^{-1}$ and/or HI $1.6 \mathrm{mg} \mathrm{mL}^{-1}$. Untreated mycobacterial cells served as controls. Performed at $40 \times$ magnification. 
Lower total fluorescence of the M. intracellulare biofilm and a lower number of cells in the biofilm (Figure 6) may indicate both biofilm destruction and cell detachment due to EO action.
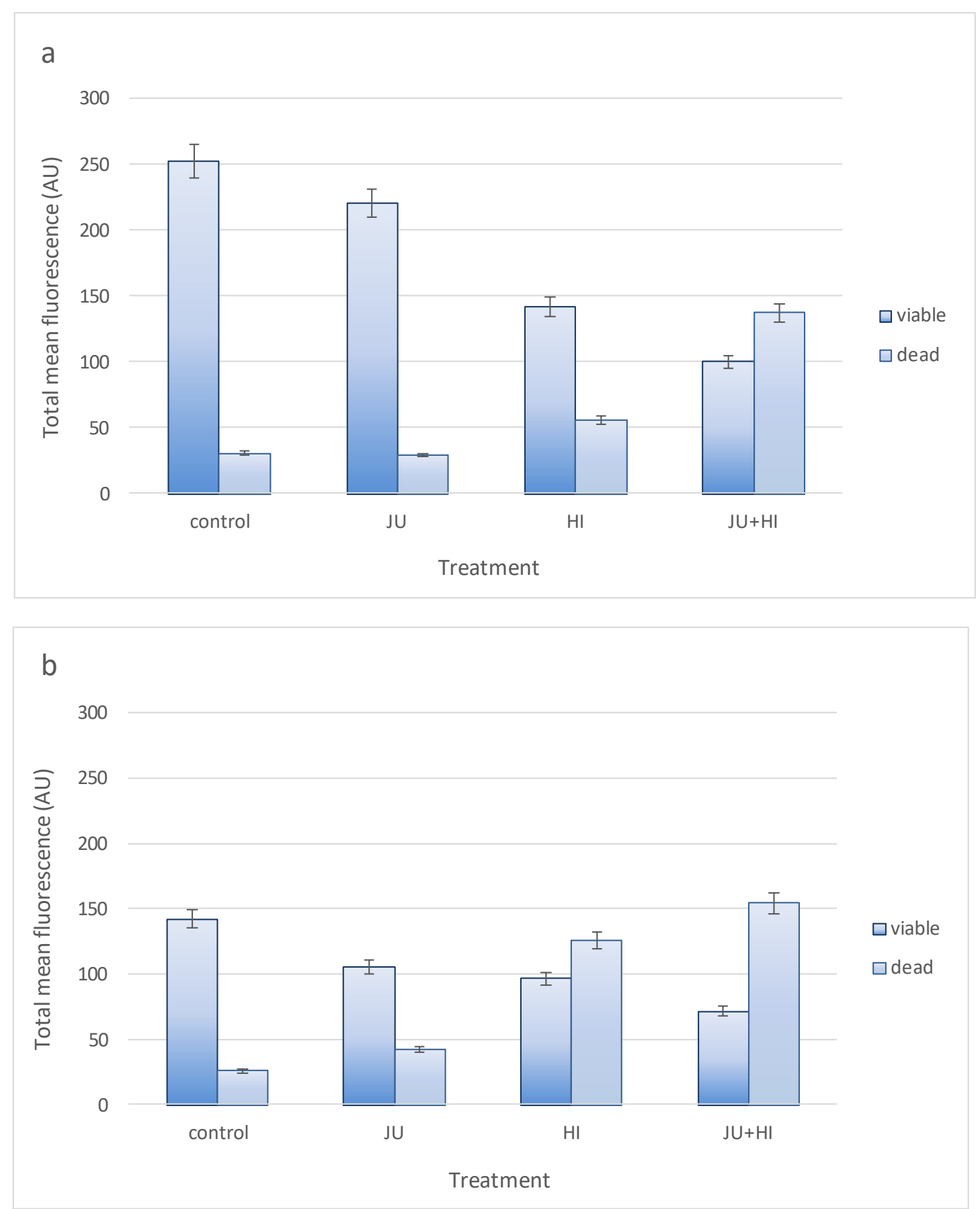

Figure 6. Total mean fluorescence measured for propidium iodide and SYTO ${ }^{\circledR} 9$ stained biofilms of M. avium (a) and M. intracellulare (b) on stainless steel discs, as visualized with confocal laser scanning microscopy (control, three-day-old biofilm of $M$. avium treated for $22 \mathrm{~h}$ with $0.8 \mathrm{mg} \mathrm{mL}^{-1} \mathrm{~J}$. communis $\mathrm{EO}$ (JU) and/or $0.012 \mathrm{mg} \mathrm{mL}^{-1} \mathrm{H}$. italicum EO (HI), and three-day-old biofilm of M. intracellulare treated for $22 \mathrm{~h}$ with $0.8 \mathrm{mg} \mathrm{mL}^{-1} \mathrm{~J}$. communis EO (JU) and/or $1.6 \mathrm{mg} \mathrm{mL}^{-1}$ H. italicum EO (HI). The experiment was repeated twice and a minimum of three images were analyzed and the mean fluorescence \pm SD is shown. 


\section{Discussion}

Mycobacterium avium and other NTMs belong to the specific group of waterborne microorganisms named opportunistic premise plumbing pathogens, which are normal inhabitants of premise plumbing systems and can cause infections in immunocompromised patients $[12,40]$.

Cell wall hydrophobicity and aggregation ability in liquid media are key factors in their pathogenicity and biofilm formation as well as play a crucial role in NTM resistance to disinfectants, acidic environments, and high ambient temperatures. The growth of NTM in the form of biofilms on glass, copper, galvanized steel or plastic results in their resistance to antimicrobials and disinfectants [41,42].

Due to the extreme resistance of OPPP biofilms including those of NTM, new approaches or new substances are needed to fight biofilm formation and destruction. Our previous studies have demonstrated the great potential of EOs as inhibitors of mycobacterial adhesion or biofilm formation on polystyrene as well as inhibitors of adhesion to living cells (amoebae and HeLa cells) [27,32,33,43]. The EOs of J. communis and H. italicum from coastal regions of Croatia have been shown to be particularly effective. In this study, we used commercial EOs produced from the same manufacturer two years apart, and although deviations in the amount of $\alpha$-pinene and some other compounds can be seen, all repeated experiments gave the same MIC concentrations and synergistic effects of combinations of these two oils. Obviously, the antibacterial effect against NTM is not a result of a single dominant component, but the effect of the interaction of different components in these oils $[27,32]$.

Haziri et al. [44] found moderate to high antimicrobial activity of J. communis EO against $S$. aureus, E. coli, and Hafnia alvei, while P. aeruginosa was shown to be resistant to this oil. Klančnik et al. [24] analyzed the effect of J. communis EO on the adhesion of $C$. jejuni to AISI 304 stainless steel. They reported that the adhesion of $C$. jejuni to AISI 304 under the influence of $J$. communis $\mathrm{EO}$ was reduced by more than $90 \%$.

Monoterpenes, $\alpha$ and $\beta$-pinene, sabinene, and $\beta$-myrcene, together make up at least a quarter, and sometimes more than two-thirds of the chemical composition of J. communis and $H$. italicum EO, with the remainder consisting of sesquiterpenes, primarily $\gamma$-curcumene and neryl acetate. However, when we tested $\alpha$-pinene as an individual compound against M. avium and M. intracellulare, its MIC/MBC/MIC values were three times higher than those of the J. communis $\mathrm{EO}$ and twice as high as those of the H. italicum EO [27]. In an experiment with M. gordonae, $\alpha$-pinene had the same MIC value as J. communis EO, however, the MBC and MIC values were two and three times higher, respectively. We could assume that the antimycobacterial activity of J. communis $\mathrm{EO}$ and H. italicum $\mathrm{EO}$ can be attributed to $\alpha$-pinene, but it is more likely that it could be due to the synergistic activity of several major compounds within these EOs.

M. avium, M. intracellulare, and M. gordonae demonstrated an abundant biofilm forming ability on stainless steel in STW. In our previous study, M. avium and M. intracellulare formed biofilms on polystyrene, but the number of bacteria was lower by two logarithmic units than in this study [32]. M. avium produced larger volume biofilms than M. intracellulare, which coincides with data from research studies [4]. The highest degree of adhesion of $M$. avium was observed on galvanized stainless steel, followed by stainless steel, polyvinyl chloride, glass, and copper. Factors enhancing the adhesion of M. avium to the surface are the roughness and hydrophobicity of the substrate as well as the presence of zinc, calcium, and magnesium [41]. Fast-growing and saprophytic species of $M$. chelonae, M. fortuitum, $M$. gordonae, and $M$. tarrae were identified in $90 \%$ of the polymicrobial biofilms found in the water supply systems of households and water treatment plants. In polymicrobial biofilms, M. avium, M. intracellulare, and M. xenopi, are predominantly present on faucets and shower heads [14]. It has been observed that Methylobacterium spp., like M. avium, rapidly forms a biofilm of a characteristic pink color in water supply systems [45].

Esteban et al. [46] studied biofilm formation by unpigmented fast-growing mycobacteria on a plastic surface in three different media. Biofilm formation was monitored at 
room temperature in Middlebrook 7H9S, STW, and phosphate buffered saline with 5\% glucose (PBS 5\% GLU). All the examined/analyzed species showed a sigmoid growth curve in 7H9S and STW. In 7H9, they initially had a characteristic lacy growth pattern with a delicate reticulate structure, which was then firmly formed and covered the entire surface by the 28th day of incubation. In STW, they showed the same growth pattern, but the fully developed biofilm was formed only on day 63, while in PBS 5\% GLU, they did not manage to cover the entire surface within 69 days. It has long been known that low-nutrient media reduce the amount of biofilm produced by slow-growing NTMs [45]. However, in a study by Esteban et al. [46], STW was observed to be a better biofilm development medium than PBS 5\% GLU. The authors concluded that such behavior may be due to a multitude of chemicals present at low levels in STW, serving as nutrients for mycobacteria. Ambient temperature was recognized as another important factor affecting biofilm development. Incubation of cultures was performed at room temperature, naturally present in the environment [46]. Our study into the effects of temperature on the mycobacterial biofilm formation revealed a temperature of $25{ }^{\circ} \mathrm{C}$ to be the most favorable for biofilm formation. At this temperature, J. communis EO showed the weakest anti-adhesion and antibiofilm activity against NTM on polystyrene [33].

M. gordonae is a saprophytic, environmental NTM. According to our study, M. gordonae on stainless steel AISI 316 in STW, after 72 hours, produced a significantly larger volume biofilm than $M$. avium and $M$. intracellulare, which confirmed previous observations found in scientific papers of a significant presence of $M$. gordonae in the biofilm on metal surfaces of water supply systems [13]. NTMs in the aqueous medium showed greater sensitivity to the action of J. communis $\mathrm{EO}$ and H. italicum $\mathrm{EO}$, than was observed in the nutritive liquid medium 7H9S [27]. The reason for this may be that nutrient-rich broth stimulates the multiplication of mycobacteria, which makes them more sensitive to the effect of EOs, or it could be due to the greater solubility of EOs in this nutrient-rich medium. In contrast, an aqueous medium slows down the multiplication of mycobacteria and promotes their resistance.

The degradation of three-day biofilms of M. avium, M. intracellulare, and M. gordonae on AISI 316 was most strongly affected by $\mathrm{H}$. italicum $\mathrm{EO}$ at a concentration of $2 \times \mathrm{MIC}$. The greatest degree of degradation of biofilm, at this concentration of H. italicum EO, was observed in M. gordonae, followed by M. avium, whereas the most resistant was the biofilm of $M$. intracellulare. Thus, in studies conducted with M. gordonae and M. avium, we revealed its exceptional ability to form a biofilm. However, the biofilm of M. gordonae, in contrast to the biofilm of M. avium and M. intracellulare, is more sensitive to degradation caused by $H$. italicum and J. communis EO activity.

Increased resistance of M. avium biofilm was observed by Carter et al. [47] who recently reported that clarithromycin could inhibit $M$. avium if administered before the formation of a biofilm in the respiratory system and becomes ineffective after the formation of a biofilm by this mycobacterium. Due to the altered $M$. avium phenotype in the biofilm, its response to antimicrobial therapy is limited, which is a key problem in the treatment of pulmonary mycobacteriosis caused by this mycobacterium [48]. The most likely explanation for the synergistic action of the EOs is that compounds from each EO have a different target site, combined with improved diffusion and distribution of each EO and components in the bacterial cell, inhibition of common biochemical pathway, inhibition of protective enzymes, and action on the specific resistance mechanism [20,49].

\section{Conclusions}

Our study showed that the tested EOs, when used at subinhibitory synergistic concentrations, had a greater effect on the degradation of mycobacterial biofilms grown on stainless steel than when they were applied individually at inhibitory concentrations. This allowed for the application of low non-toxic concentrations in biofilm eradication. Synergistic combinations of J. communis and H. italicum EOs could therefore potentially be applied in new ways to prevent the adhesion and biofilm formation of NTM, not only in the water 
supply system as a reservoir of NTM and a source of human infections, but also on artificial materials used in medicine or in the case of infections associated with biofilm formation.

Author Contributions: Conceptualization, D.P. and I.G.; Formal analysis, D.P., Z.M., L.K., and I.G.; Methodology, D.P., Z.M., L.K., and I.G.; Investigation, D.P., Z.M., and I.G.; Validation, All authors; Data curation, D.B., D.P., and I.G.; Funding acquisition, I.G., Ž.M., and D.B.; Project administration, I.G., Ž.M., and D.B.; Resources, I.G., Ž.M., and D.B.; Visualization, L.K., I.G., and Ž.M.; Supervision, I.G.; Writing—original draft, D.P., Z.M., Ž.M., D.B., and I.G.; Writing-review and editing, I.G., D.B., and Ž.M. All authors have read and agreed to the published version of the manuscript.

Funding: The research described here was funded by grants from the University of Rijeka (uniribiomed-18-171, uniri-biomed-18-155-1304, uniri-prirod-18-302).

Institutional Review Board Statement: Not applicable.

Informed Consent Statement: Not applicable.

Data Availability Statement: Not applicable.

Acknowledgments: We are grateful to Meta Sterniš, from the Biotechnical Faculty of the University of Ljubljana for the donation of the stainless steel discs.

Conflicts of Interest: The authors declare no conflict of interest.

\section{References}

1. Cambau, E.; Drancourt, M. Steps towards the discovery of Mycobacterium tuberculosis by Robert Koch, 1882. Clin. Microbiol. Infect. 2014, 20, 196-201. [CrossRef]

2. $\quad$ Forbes, B.A.; Hall, G.S.; Miller, M.B.; Novak, S.M.; Rowlinson, M.C.; Salfinger, M.; Somoskovi, A.; Warshauer, D.M.; Wilson, M.L. Practice Guidelines for Clinical Microbiology Laboratories: Mycobacteria. Clin. Microbiol. Rev. 2018, 31. [CrossRef]

3. Sousa, S.; Bandeira, M.; Carvalho, P.A.; Duarte, A.; Jordao, L. Nontuberculous mycobacteria pathogenesis and biofilm assembly. Int. J. Mycobacteriol. 2015, 4, 36-43. [CrossRef]

4. Faria, S.; Joao, I.; Jordao, L. General Overview on Nontuberculous Mycobacteria, Biofilms, and Human Infection. J. Pathog. 2015, 2015, 809014. [CrossRef]

5. Pfyffer, G.E.; Brown-Elliott, B.A.; Wallace, R.J.J. Mycobacterium: General Characteristics, Isolation, and Staining Procedures. In Manual of Clinical Microbiology, 8th ed.; Murray, P.R., Ed.; American Society of Microbiology: Washington, DC, USA, 2003; Volume 1, pp. 532-584.

6. Vincent, V.; Brown-Elliott, B.A.; Jost, K.C.; Wallace, R.J.J. Mycobacterium: Phenotypic and Genotypic Identification. In Manual of Clinical Microbiology, 8th ed.; Murray, P.R., Ed.; American Society of Microbiology: Washington, DC, USA, 2003; Volume 1, pp. 560-584.

7. Jankovic, M.; Zmak, L.; Krajinovic, V.; Viskovic, K.; Crnek, S.S.; Obrovac, M.; Haris, V.; Jankovic, V.K. A fatal Mycobacterium chelonae infection in an immunosuppressed patient with systemic lupus erythematosus and concomitant Fahr's syndrome. J. Infect. Chemother. 2011, 17, 264-267. [PubMed]

8. Halstrom, S.; Price, P.; Thomson, R. Review: Environmental mycobacteria as a cause of human infection. Int. J. Mycobacteriol 2015, 4, 81-91. [CrossRef] [PubMed]

9. Nishiuchi, Y.; Iwamoto, T.; Maruyama, F. Infection Sources of a Common Non-tuberculous Mycobacterial Pathogen, Mycobacterium avium Complex. Front. Med. 2017, 4, 27. [CrossRef] [PubMed]

10. Tortoli, E. Clinical manifestations of nontuberculous mycobacteria infections. Clin. Microbiol. Infect. 2009, 15, 906-910. [CrossRef] [PubMed]

11. De Groote, M.A.; Huitt, G. Infections due to rapidly growing mycobacteria. Clin. Infect. Dis. 2006, 42, 1756-1763. [CrossRef]

12. Falkinham, J.O.; Pruden, A.; Edwards, M. Opportunistic Premise Plumbing Pathogens: Increasingly Important Pathogens in Drinking Water. Pathogens 2015, 4, 373-386. [CrossRef] [PubMed]

13. Feazel, L.M.; Baumgartner, L.K.; Peterson, K.L.; Frank, D.N.; Harris, J.K.; Pace, N.R. Opportunistic pathogens enriched in showerhead biofilms. Proc. Natl. Acad. Sci. USA 2009, 106, 16393-16399. [CrossRef]

14. Richards, J.P.; Ojha, A.K. Mycobacterial Biofilms. Microbiol. Spectr. 2014, 2, 1-11. [CrossRef] [PubMed]

15. Hall-Stoodley, L.; Keevil, C.W.; Lappin-Scott, H.M. Mycobacterium fortuitum and Mycobacterium chelonae biofilm formation under high and low nutrient conditions. J. Appl. Microbiol. 1998, 85 (Suppl. 1), 60S-69S. [CrossRef] [PubMed]

16. Nikolić, T.; Rešetnik, I. Plant uses in Croatia. Phytol. Balc. 2007, 13, 229-238.

17. Malenica Staver, M.; Gobin, I.; Ratkaj, I.; Petrović, M.; Vulinović, A.; Dinarina-Sablić, M.; Broznić, D. In vitro antiproliferative and antimicrobial activity of the essential oil from the flowers and leaves of Helichrysum italicum (Roth) G. Don growing in Central Dalmatia (Croatia). J. Essent. Oil Bear. Pl. 2018, 21,77-91. [CrossRef]

18. Bakkali, F.; Averbeck, S.; Averbeck, D.; Idaomar, M. Biological effects of essential oils-A review. Food Chem. Toxicol. 2008, 46, 446-475. [CrossRef] 
19. Bag, A.; Chattopadhyay, R.R. Evaluation of Synergistic Antibacterial and Antioxidant Efficacy of Essential Oils of Spices and Herbs in Combination. PLoS ONE 2015, 10, e0131321. [CrossRef] [PubMed]

20. Bassole, I.H.; Juliani, H.R. Essential oils in combination and their antimicrobial properties. Molecules 2012, 17, 3989-4006. [CrossRef]

21. Dorman, H.J.; Deans, S.G. Antimicrobial agents from plants: Antibacterial activity of plant volatile oils. J. Appl. Microbiol. 2000, 88, 308-316. [CrossRef]

22. Newton, S.M.; Lau, C.; Wright, C.W. A review of antimycobacterial natural products. Phytother. Res. 2000, 14, 303-322. [CrossRef]

23. Sawicki, R.; Golus, J.; Przekora, A.; Ludwiczuk, A.; Sieniawska, E.; Ginalska, G. Antimycobacterial Activity of Cinnamaldehyde in a Mycobacterium tuberculosis(H37Ra) Model. Molecules 2018, 23, 2381. [CrossRef]

24. Klančnik, A.; Zorko, Š.; Toplak, N.; Kovač, M.; Bucar, F.; Jeršek, B.; Smole Možina, S. Antiadhesion activity of juniper (Juniperus communis L.) preparations against Campylobacter jejuni evaluated with PCR-based methods. Phytother. Res. 2018, 32, 542-550. [CrossRef]

25. Angioni, A.; Barra, A.; Russo, M.T.; Coroneo, V.; Dessiä, S.; Cabras, P. Chemical Composition of the Essential Oils of Juniperus from Ripe and Unripe Berries and Leaves and Their Antimicrobial Activity. J. Agric. Food Chem. 2003, 51, 3073-3078. [CrossRef]

26. Rezvani, S.; Ali Rezai, M.; Mahmodi, N. Analysis of Essential Oils of Juniperus polycarpous and Juniperus communis. Asian J. Chem. 2007, 19, 5019-5022.

27. Peruč, D.; Gobin, I.; Abram, M.; Broznić, D.; Svalina, T.; Štifter, S.; Staver, M.M.; Tićac, B. Antimycobacterial potential of the juniper berry essential oil in tap water. Arh. Hig. Rada. Toksikol. 2018, 69, 46-54. [CrossRef]

28. Mastelic, J.; Politeo, O.; Jerkovic, I. Contribution to the analysis of the essential oil of Helichrysum italicum (Roth) G. Don. Determination of ester bonded acids and phenols. Molecules 2008, 13, 795-803. [CrossRef]

29. Antunes Viegas, D.; Palmeira-de-Oliveira, A.; Salgueiro, L.; Martinez-de-Oliveira, J.; Palmeira-de-Oliveira, R. Helichrysum italicum: From traditional use to scientific data. J. Ethnopharmacol. 2014, 151, 54-65. [CrossRef] [PubMed]

30. Mancini, E.; De Martino, L.; Marandino, A.; Scognamiglio, M.R.; De Feo, V. Chemical composition and possible in vitro phytotoxic activity of Helichrsyum italicum (Roth) Don ssp. italicum. Molecules 2011, 16, 7725-7735. [CrossRef]

31. Jerkovic, I.; Marijanovic, Z.; Kus, P.M.; Tuberoso, C.I. Comprehensive Study of Mediterranean (Croatian) Propolis Peculiarity: Headspace, Volatiles, Anti-Varroa-Treatment Residue, Phenolics, and Antioxidant Properties. Chem. Biodivers. 2016, 13, 210-218. [CrossRef]

32. Peruč, D.; Tićac, B.; Abram, M.; Broznić, D.; Štifter, S.; Staver, M.M.; Gobin, I. Synergistic potential of Juniperus communis and Helichrysum italicum essential oils against nontuberculous mycobacteria. J. Med. Microbiol. 2019, 68, 703-710. [CrossRef]

33. Peruc, D.; Ticac, B.; Broznic, D.; Maglica, Z.; Sarolic, M.; Gobin, I. Juniperus communis essential oil limit the biofilm formation of Mycobacterium avium and Mycobacterium intracellulare on polystyrene in a temperature-dependent manner. Int. J. Environ. Health Res. 2020, 1-14. [CrossRef]

34. Sarker, S.D.; Nahar, L.; Kumarasamy, Y. Microtitre plate-based antibacterial assay incorporating resazurin as an indicator of cell growth, and its application in the in vitro antibacterial screening of phytochemicals. Methods 2007, 42, 321-324. [CrossRef]

35. Andrejak, C.; Almeida, D.V.; Tyagi, S.; Converse, P.J.; Ammerman, N.C.; Grosset, J.H. Characterization of mouse models of Mycobacterium avium complex infection and evaluation of drug combinations. Antimicrob. Agents Chemother. 2015, 59, $2129-2135$. [CrossRef] [PubMed]

36. Vasiljević, B.; Knežević-Vučković, J.; Mitić-Ćulafić, D.; Orčić, D.; Francišković, M.; Srdic-Rajic, T.; Jovanović, M.; Nikolić, B. Chemical characterization, antioxidant, genotoxic and in vitro cytotoxic activity assessment of Juniperus communis var. saxatilis. Food Chem. Toxicol. 2018, 112, 118-125. [CrossRef] [PubMed]

37. White, R.L.; Burgess, D.S.; Manduru, M.; Bosso, J.A. Comparison of three different in vitro methods of detecting synergy: Time-kill, checkerboard, and E test. Antimicrob. Agents Chemother. 1996, 40, 1914-1918. [CrossRef] [PubMed]

38. Balouiri, M.; Sadiki, M.; Ibnsouda, S.K. Methods for in vitro evaluating antimicrobial activity: A review. J. Pharm. Anal. 2016, 6, 71-79. [CrossRef] [PubMed]

39. Teanpaisan, R.; Kawsud, P.; Pahumunto, N.; Puripattanavong, J. Screening for antibacterial and antibiofilm activity in Thai medicinal plant extracts against oral microorganisms. J. Tradit. Complement. Med. 2017, 7, 172-177. [CrossRef] [PubMed]

40. Falkinham, J.O. Surrounded by mycobacteria: Nontuberculous mycobacteria in the human environment. J. Appl Microbiol. 2009, 107, 356-367. [CrossRef]

41. Falkinham, J.O. Mycobacterium avium complex: Adherence as a way of life. AIMS Microbiol. 2018, 4, 428-438. [CrossRef]

42. Steed, K.A.; Falkinham, J.O., 3rd. Effect of growth in biofilms on chlorine susceptibility of Mycobacterium avium and Mycobacterium intracellulare. Appl. Environ. Microbiol. 2006, 72, 4007-4011. [CrossRef]

43. Peruč, D.; Gobin, I.; Broznić, D.; Malenica Staver, M.; Tićac, B. Influence of essential oil Helichrysum italicum (Roth) G. Don on the formation of non-tuberculous mycobacterial biofilm. Med. Flum. 2018, 54, 282-289. [CrossRef]

44. Haziri, A.; Faiku, F.; Mehmeti, A.; Govori, S.; Abazi, S.; Daci, M.; Haziri, I.; Bytyqi-Damoni, A.; Mele, A. Antimicrobial properties of the essential oil of Juniperus communis (L.) growing wild in east part of Kosovo. Am. J. Pharmacol. Toxicol. 2013, 8, 128-133. [CrossRef]

45. Munoz Egea, M.C.; Ji, P.; Pruden, A.; Falkinham Iii, J.O. Inhibition of Adherence of Mycobacterium avium to Plumbing Surface Biofilms of Methylobacterium spp. Pathogens 2017, 6, 42. [CrossRef] 
46. Esteban, J.; Martin-de-Hijas, N.Z.; Kinnari, T.J.; Ayala, G.; Fernandez-Roblas, R.; Gadea, I. Biofilm development by potentially pathogenic non-pigmented rapidly growing mycobacteria. BMC Microbiol. 2008, 8, 184. [CrossRef] [PubMed]

47. Carter, G.; Wu, M.; Drummond, D.C.; Bermudez, L.E. Characterization of biofilm formation by clinical isolates of Mycobacterium avium. J. Med. Microbiol. 2003, 52, 747-752. [CrossRef]

48. Yamazaki, Y.; Danelishvili, L.; Wu, M.; Hidaka, E.; Katsuyama, T.; Stang, B.; Petrofsky, M.; Bildfell, R.; Bermudez, L.E. The ability to form biofilm influences Mycobacterium avium invasion and translocation of bronchial epithelial cells. Cell Microbiol. 2006, 8 , 806-814. [CrossRef] [PubMed]

49. Langeveld, W.T.; Veldhuizen, E.J.; Burt, S.A. Synergy between essential oil components and antibiotics: A review. Crit. Rev. Microbiol. 2014, 40, 76-94. [CrossRef] [PubMed] 